\title{
Ovine Footrot and Its Clinical Management
}

\author{
Haben Fesseha (1D) \\ School of Veterinary Medicine, Wolaita \\ Sodo University, Wolaita Sodo, Ethiopia
}

\begin{abstract}
Footrot is one of the most important causes of lameness and economic losses in sheep and goat production worldwide. A 2-years-old ram was presented to the college of veterinary science teaching hospital, Mekelle University, with a history of non-weight bearing lameness of the left hindlimb. The hoof was damaged, split and the interdigital space was full of dirt and the scent of a rotten smell. On clinical examination, the sheep was suffering from depression, weight loss, with elevation in the physiological parameters such as a rectal temperature of $40.1^{\circ} \mathrm{C}$, heart rate of 96 beats per minute, and respiratory rate of 40 breaths per minute. The hoof was carefully washed with isotonic saline solution and disinfected with hydrogen peroxide $3 \%$ and povidone-iodine $1 \%$. Additionally, meloxicam $(0.5 \mathrm{mg} / \mathrm{kg}, \mathrm{IM})$ thrice daily for three days and oxytetracycline $10 \%(10 \mathrm{mg} / \mathrm{kg}, \mathrm{IM})$ for successive 5 days were administered parenterally. The infected surface was also treated with topical oxytetracycline spray for five days. The sheep have recovered after 7 days of treatment with significant improvement in the hoof injury. Successful management of footrot in Abergele sheep is discussed in the current case report.
\end{abstract}

Keywords: Abergele sheep, clinical management, footrot, lameness

\section{Introduction}

Footrot is a contagious disease of cattle, sheep, and goats, and possibly other ruminants, although the clinical severity in these animals is much less than in sheep. It is caused by the simultaneous actions of Fusobacterium necrophorum and Dichelobacter nodosus (earlier known as Bacteroides nodosus) and characterized by a chronic bacterial infection that is confined to the epidermal tissues of the interdigital skin and horn of the hoof. Besides, the demolition of the hard keratin coating on the hoof is one of the main characteristics and results in lameness in most cases. Footrot is distinguished by the smell of the hoof epidermical tissues, inflammatory exudates, and necrosis. ${ }^{1-4}$

Contagious ovine footrot is the most limiting disease and it was initially described in 1869. It is a costly disease to the sheep industry due to the cost of treatment and labor, drugs and equipment, decreased flock productivity, and losses from sales of breeding stock. All these results in significant economic hardship for animal producers worldwide. ${ }^{5,6}$ In sheep, $90 \%$ of lameness cases are caused by footrot (Dichelobacter nodosus). ${ }^{7}$ The virulent and benign are the two forms of the disease that are well-studied and described. The most economically virulent form of the disease presents a great burden on the development and welfare of livestock. ${ }^{6,8,9}$

The clinical signs associated with ovine footrot depend on factors such as the virulence of the organism, the climatic environment, the health or trauma to the interdigital skin, and several host factors. Lameness is typically the main sign of a diseased
Correspondence: Haben Fesseha Email haben.senbetu@wsu.edu.et 
sheep, though sheep with an initial infection may not reveal lameness. ${ }^{2}$ The diverse and complex transmission of footrot involves the use of multiple etiologic agents, frequently complicated or reinforced by the environmental, host, and genetic factors, stock rate, and nutritional efficacy. ${ }^{1,4}$ Induction and development of the disease procedures are carried out by Fusobacterium necrophorum, while Dichelobacter nodosus is the transmission agent. ${ }^{8,10}$ Moreover, overgrown feet, recurrent or high rainfall for numerous weeks and low temperature typically under $10^{\circ} \mathrm{C}$ are the major factors for the transmission and most outbreaks of footrot. ${ }^{2,11}$

According to Raadsma and Egerton, wet Season raises footrot vulnerability since it affects the physical structure of the hoof making it more susceptible to the disease. ${ }^{8}$ Despite the organism's biology that suggested D. nodosus needs no oxygen for growth, the pathogen can remain exposed to air for up to 10 days and can be transmitted through soil contact, indicating that the stocking rate of new animals can dramatically decrease the speed of D. nodosus from a flock. Also, studies have demonstrated that footrot management is difficult due to the capacity of the pathogen to survive in the open air and transmit via contact with the soil. ${ }^{1,3,12}$

Footrot should be differentially diagnosed from other hoof problems that cause lameness. Hoof separation, white line lesions, foot abscesses, sole ulcerations and abscesses, hoof injuries due to foreign bodies, granulomatous lesions, and severely overgrown or deformed feet are other hoof problems that are seen on the farm that resembles footrot. ${ }^{1,11,13,14}$ Besides, treponeme infection, laminitis, and primary claw horn lesions with secondary infections were still regarded as likely diagnoses. Thus, detailed clinical examination and laboratory diagnostics should be carried out to differentiate further., ${ }^{2,8}$

Accordingly, control measures are the most practical way to decrease footrot inception and severity but it is costly. Quarantine of infected sheep, footbaths/soaks, topical medication with zinc and copper sulfate, use of appropriate antibiotics based on microbial sensitivity, vaccination, and combination of the above should be considered as control measures for footrot. However, It is also no guarantee that the disease cannot recur again if control measures are employed. ${ }^{1,11,12,15}$ The current case report describes the successful management of footrot in Abergele sheep from farms in Mekelle, Ethiopia.

\section{Report of the Clinical Case General Description of the Sheep Farm}

The current case was conducted in one of the smallholder sheep farm located in the peri-urban area of Mekelle city. In the area, there were different types of farms constructed for dairy and beef production. The wall of the sheep pen was constructed from galvanized steel and the floor was made of concrete. The pen was unhygienic where it was only cleaned once a week. The farm area was found in mid-altitude and receives a mean annual rainfall ranging from 1500 to $2000 \mathrm{~mm}$. The case was reported during the autumn (March and April) which is one of the wet seasons of the area. Even though the biosecurity and husbandry practice of the farm was poor, the sheep were treated and vaccinated against different diseases such as ectoparasites, acidosis, pasteurellosis, and sheep pox.

\section{Clinical Examination and Presentation of Hoof Lesions}

A two-years-old ram of Abergele breed weighing around $23 \mathrm{~kg}$ was submitted to Veterinary Teaching Hospital of Mekelle, Ethiopia with a complaint of walking difficulty due to lesion and injury at the left hindlimb. The owner has raised the sheep intensively and isolated as the condition worsens. The case was reported during the autumn (March and April). On presentation, the ram was dull, depressed with reduced appetite, lameness, and swelling on the interdigital space of the hoof. The detailed physical and clinical examination revealed slough-off and accumulation of necrotic tissue and dirt particles on the ulcerated hoof (Figure 1B) together with foul-smelling pus on the interdigital space of the left hindlimb and the presence of heel erosion in the affected part of the hoof (Figure 1A).

The clinical parameters were elevated beyond the normal range such as rectal temperature $\left(40.1^{\circ} \mathrm{C}\right)$, heart rate

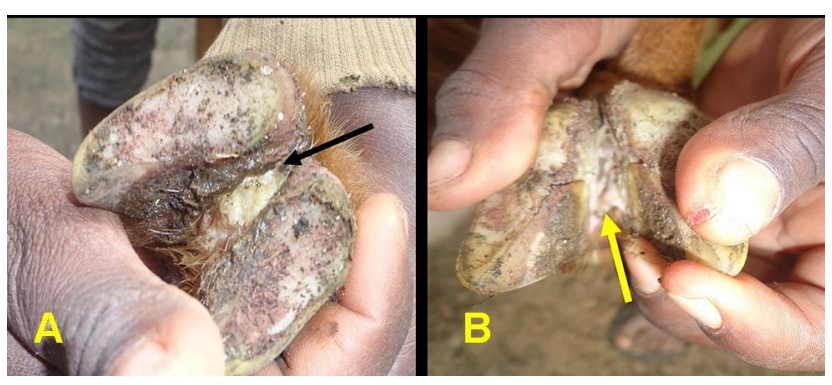

Figure I Clinical presentation of footrot on left hindlimb in adult ram with an accumulation of pus and presence of heel erosion (Arrow) (A) and slough-off and accumulation of necrotic tissue in the interdigital space (Arrow) (B). 
(96 beats per minute), and respiratory rate ( 24 breaths per minute). Besides, the owner also complained that other sheep from the same flock as well as nearby farms were previously showing similar signs of footrot with varying degrees of lameness and treated only with oxytetracycline (10\%) injection for three consecutive days. Based on history, clinical examination, and findings, the case was diagnosed as footrot and was managed using washing, disinfection, and antibiotic treatment.

\section{Treatment, Follow-Up, and Outcome of the Disease}

The ram was restrained in lateral recumbency and the hoof was thoroughly cleaned using isotonic saline solution and further disinfected using hydrogen peroxide 3\% followed by povidone-iodine $1 \%$. The sheep was then treated with different antibiotic and anti-inflammatory drug. Parenterally, Oxytetracycline $(10 \mathrm{mg} / \mathrm{kg}$, IM) was administered for five successive days followed by Meloxicam $(0.5 \mathrm{mg} / \mathrm{kg}, \mathrm{IM})$ thrice daily for three days to reduce inflammation at the injury site and lameness. Besides, Tetracycline wound spray was also applied around the injured hoof after parenteral administration as well as on the second and third day after cleaning the injured area.

Upon follow-up, dressing of the injured hoof was done using a $1 \%$ povidone-iodine solution at second- and thirddays post-treatment up to 7-days until the wound is dried and showed good recovery (Figure 2A-C). Interestingly, the ram has showed good prognosis and the wounded hoof has changed dramatically. After four weeks of follow-up, the overall health and welfare of the ram also was assessed and was found under good status. The farmer was advised to regularly clean the floors and provide them with quality feedstuff to promote the healing of the injured hoof. It was also recommended to wash the hoof on regular basis to avoid soil and litter contamination.

\section{Discussion and Conclusion}

Footrot is an infectious, contagious disease that frequently affecting sheep as compared to the goat and causes severe lameness and economic loss due to decreased flock production, premature culling of animals, loss of body weight gains, decrease reproduction and production rates. ${ }^{7,16}$ The presence of severe hoof lesions is accompanied by lameness sheep in the present case report was comparable with the previous report of Knappe-Poindecker et al, ${ }^{17} \mathrm{König}$ et al, ${ }^{15}$ and Bennett and Hickford, ${ }^{1}$ who stated footrot is more prevalent in sheep as compared to goats. However, Bitrus et al, ${ }^{11}$ reported the high prevalence of footrot in goat. Cross-infection of footrot was also reported in sheep co-grazing with cattle ${ }^{17}$ that might be a possible attributing factor for the occurrence of footrot in the current case report of the study farm.

Studies have shown that the effect of soil, manure, and grass on the interdigital part of the hoof is attributable to the dirty surrounding. This, in turn, causes the loss of integrity of skin and predisposes the digits for invasion by $F$. necrophorum that resulted in severe dermatitis and subsequently lameness. $^{2,18}$ Dichelobacter nodosus is the principal agent of the disease; however, a synergistic measure should be taken to deter infection, with the soil and feces normally inhabitant for Fusobacterium necrophorum. F. necrophorum causes interdigital dermatitis in animals that permits the digit invasion by D. nodosus. $5,6,11,19$

The environmental conditions have a great role in the viability and survivability of the organism. According to different studies, the bacterium cannot last for over 10 days in the surrounding. ${ }^{8,11,20}$ Thus, recurrent barn (pens) cleaning can minimize beginning and infection severity.

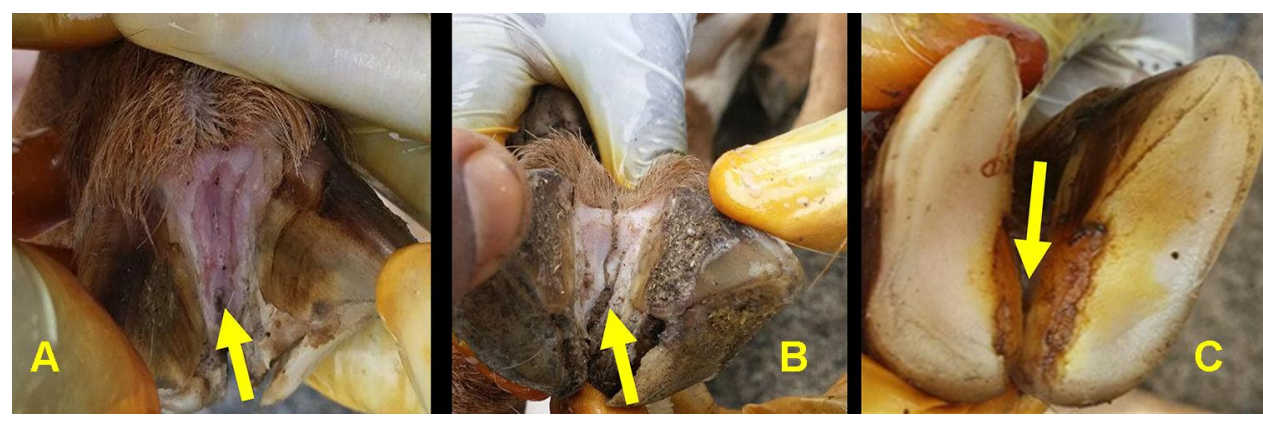

Figure 2 Clinical management of injured foot using povidone-iodine (Arrow) (A), deep ulcer using hydrogen peroxide (Arrow) (B), the progress of the injured hoof after 7 days of treatment (Arrow) (C). 
Besides, warm wet weather, interdigital skin, overgrowth of hoof and contaminated (urine and feces) habitats, and hosting dramatically increase disease onset and propagation among animals. ${ }^{5}$ This situation in agreement with the result of this case report in terms of predisposing factors.

Similarly, the inter-digital space of the hoofs was filled with mud and feces in this case report. Foot lesions especially deep-rooted lesions increases the chance of contamination and infection with pyogenic bacteria which can cause foul abscess due to pyogenic bacteria behavior and odor. ${ }^{5,11}$ This situation is agreed with the finding of this case report in terms of infection and clinical presentation of the case.

The most important health signs observed in footrot are foot lameness along with various degrees of discomfort and typical foot lesions. A footrot diagnosis is made based on the history, clinical appearance, and seriousness of foot injuries. Besides, confirmatory diagnosis can be achieved through a bacteriological test for D. nodosus and F. necrophorum, which can be detected by Gram staining and microscopy. PCR of cultures isolated from the hoof region can also be carried out. ${ }^{6,15}$ Collaborative approaches are required to reduce the onset and severity of footrot as well as preventing the predisposing factors. According to different studies, the eradication of footrot in a herd is possible. ${ }^{10}$ This was in agreement with this case report in terms of diagnosis and prevention approaches.

Besides, an intervention strategy should be used at the early stage of the transmission period to achieve a successful eradication programme. This helps to reduce the amount of already contaminating materials in the area, to improve the animal's tolerance to infection, and to avoid an interdigital infection beginning from mild to severe. In addition, eradication programs should be structured to minimize and not eliminate all the infection focus points. ${ }^{6}$

The injured hoof was clinically managed after proper physical restraining. Then, the infected hoof was cleaned thoroughly using isotonic saline solution followed by povidone-iodine $1 \%$ and hydrogen peroxide $3 \%$ to make the area aseptic. Besides, the ram was then administered with meloxicam to reduce pain and inflammation at the injured site, followed by Oxytetracycline injection and topical tetracycline spray. The ram showed good recovery and recovered after one week of treatment. This was consistent with the previous case report of footrot in a goat in terms of case handling and management. ${ }^{11}$

Accordingly, footrot can be managed by using the combination of these procedures including disinfecting (isotonic saline solution povidone-iodine $1 \%$ and hydrogen peroxide 3\%) together with antibiotics (Oxytetracycline $10 \%$ and Oxytertracycline spray) and recommended as an alternative technique. This idea was supported by the previous report that recommends using different combinations to eradicate footrot. In the previous studies, it is also obvious that no single therapy is effective. It has to be a combination that best suits the owner/installations, manager's administration, and financial limitations. ${ }^{11,21}$ Thus, it is recommended for further study on the isolation of the specific etiological agents of footrot using bio-typing and Polymerase chain reaction (PCR) investigation.

\section{Ethics Approval and Consent to Participate}

The best practice guidelines for veterinary care were followed and the sheep owner was informed as to the purpose of the study, and the Wolaita Sodo University of Research Ethics and Review Committee approved the verbally informed consent process in the manuscript.

\section{Disclosure}

The author reports no conflicts of interest in this work.

\section{References}

1. Bennett G, Hickford J. Ovine footrot: new approaches to an old disease. Vet Microbiol. 2011;148:1-7. doi:10.1016/j.vetmic.2010.0 9.003

2. Groenevelt M, Anzuino K, Smith S, et al. A case report of lameness in two dairy goat herds; a suspected combination of nutritional factors concurrent with treponeme infection. BMC Res Notes. 2015;8:791. doi:10.1186/s13104-015-1734-3

3. Winter JR, Kaler J, Ferguson E, et al. Changes in prevalence of, and risk factors for, lameness in random samples of English sheep flocks: 2004-2013. Prev Vet Med. 2015;122:121-128. doi:10.1016/j. prevetmed.2015.09.014

4. Beveridge WIB. Foot-rot in sheep: preliminary note on aetiology and possibility of control. J Counc Sci Ind. 1935;8:308-315.

5. Aguiar G, Simões SV, Silva TR, et al. Foot rot and other foot diseases of goat and sheep in the semiarid region of northeastern Brazil. Pesqui Vet Bras. 2011;31:879-884. doi:10.1590/S0100-736X20110 01000008

6. Wani S, Samanta I. Current understanding of the aetiology and laboratory diagnosis of footrot. Vet J. 2006;171:421-428. doi:10.1016/j. tvjl.2005.02.017

7. Kaler J, Green L. Naming and recognition of six-foot lesions of sheep using written and pictorial information: a study of 809 English sheep farmers. Prev Vet Med. 2008;83:52-64. doi:10.1016/j.prevetme d.2007.06.003

8. Raadsma H, Egerton J. A review of footrot in sheep: aetiology, risk factors and control methods. Livest Sci. 2013;156(1-3):106-114. doi:10.1016/j.livsci.2013.06.009

9. Zhou H, Bennett G, Hickford JG. Variation in Fusobacterium necrophorum strains present on the hooves of footrot infected sheep, goats and cattle. Vet Microbiol. 2009;135:363-367. doi:10.1016/j. vetmic.2008.09.084 
10. Abbott K, Lewis C. Current approaches to the management of ovine footrot. Vet J. 2005;169(1):28-41. doi:10.1016/j.tvj1.2004.05.008

11. Bitrus AA, Abba Y, Jesse FFA, et al. Clinical management of footrot in goats: a case report of lameness. J Adv Vet Anim Res. 2017;4:110-116. doi:10.5455/javar.2017.d195

12. Kimberling CV, Ellis RP. Advances in the control of foot rot in sheep. Vet Clin North Am Food Anim Pract. 1990;6:671-681.

13. Vatn S, Hektoen L, Høyland B, et al. Surveillance, control and eradication of footrot in Norway. Proceeding of the 7th International Sheep Veterinary Congress; June 12-16, 2009: 120.

14. Øverås J. Contagious claw disease in sheep. A review of imports and outbreaks in Norway. Småfenytt. 1994;1:29-33.

15. König U, Nyman A-KJ, de Verdier K. Prevalence of footrot in Swedish slaughter lambs. Acta Vet Scand. 2011;53:27. doi:10.1186/ 1751-0147-53-27

16. Ghimire S, Egerton J, Dhungyel O. Transmission of virulent footrot between sheep and goats. Aust Vet J. 1999;77:450-453. doi:10.1111/ j.1751-0813.1999.tb12091.x
17. Knappe-Poindecker M, Gilhuus M, Jensen TK, et al. Cross-infection of virulent Dichelobacter nodosus between sheep and co-grazing cattle. Vet Microbiol. 2014;170:375-382. doi:10.1016/j.vetmic.2014.0 2.044

18. Winter A. Lameness in sheep. Small Rumin Res. 2008;76:149-153. doi:10.1016/j.smallrumres.2007.12.008

19. Tadich N, Hernández M. Prevalencia de lesiones podales en ovinos de 25 explotaciones familiares de la provincia de Valdivia, Chile. [Prevalence of foot injuries in sheep from 25 family farms in the province of Valdivia, Chile]. Arch Med Vet. 2000;32:63-74. doi:10.4067/S0301-732X2000000100008. Spanish.

20. Green L, George T. Assessment of current knowledge of footrot in sheep with particular reference to Dichelobacter nodosus and implications for elimination or control strategies for sheep in Great Britain. Vet J. 2008;175:173-180. doi:10.1016/j.tvj1.2007.01.014

21. Whittier WD, Umberger SH. Control, Treatment, and Elimination of Foot Rot from Sheep. Virginia Cooperative Extension; 2010:1-4.

\section{Publish your work in this journal}

Veterinary Medicine: Research and Reports is an international, peerreviewed, open access journal publishing original research, case reports, editorials, reviews and commentaries on all areas of veterinary medicine. The manuscript management system is completely online and includes a very quick and fair peer-review system. Visit http://www.dovepress.com/testimonials.php to read real quotes from published authors.

Submit your manuscript here: http://www.dovepress.com/veterinary-medicine-research-and-reports-journal 